\title{
Lung function measurement in awake young children
}

\author{
H. Bisgaard, B. Klug
}

\begin{abstract}
Lung function measurement in awake young children. H. Bisgaard, B. Klug. CERS Journals Ltd 1995.

ABSTRACT: The aim of the study was to evaluate methods applicable in a clinical setting for monitoring of changes in lung function in awake young children.

Impedance measurements by the impulse oscillation technique (ZIOS), respiratory resistance measurements by the interrupter technique $(R$ int $)$ and transcutaneous measurements of oxygen tension $\left(\mathrm{Ptc}, \mathrm{O}_{2}\right)$ were compared with concomitant measurements of specific airway resistance ( $R$ aw) and forced expiratory volume in one second (FEV1) by whole body plethysmography and spirometry, respectively, during methacholine challenge in 21 young children aged 4-6 yrs, with suspected asthma. Measurements with each technique were repeated after each challenge step. A special face-mask was developed with an integrated mouthpiece which ensured mouth breathing during the measurements.

The order of sensitivity of the techniques to assess methacholine-induced changes in lung function was ZIOS $>\mathrm{sRaw}>\boldsymbol{P t c}_{\mathrm{t}} \mathrm{O}_{2}>\mathrm{FEV} 1>\boldsymbol{R}$ int. ZIOS was significantly more sensitive than all subsequent methods, and $P \mathrm{tc}, \mathrm{O}_{2}$ was significantly more sensitive than FEV1. ZIOs, sR aw and Rint, but not $P$ tc, $O_{2}$ and FEV1, detected the subclinical increase in bronchial muscle tone in the children during baseline, which was revealed by the significantly reduced airway obstruction after inhalation of a $\beta_{2}$-agonist as compared to baseline.

It is concluded that $\mathrm{ZIOS}, \boldsymbol{R}$ int and $P \mathrm{tc}, \mathrm{O}_{2}$ change in parallel with $\mathrm{S} R$ aw and FEV1 and with a comparable sensitivity during simultaneous measurements of the response to methacholine in young children aged 4-6 yrs. This implies that ZIOs, Rint and Ptc, $\mathrm{O}_{2}$ provide convenient indices of changes in lung function. Their combined use will be useful for monitoring airway diseases of young children.
\end{abstract}

Eur Respir J., 1995, 8, 2067-2075.

Dept of Pediatrics, National University Hospital, Rigshospitalet, Copenhagen, Denmark.

\author{
Correspondence: H. Bisgaard \\ Rigshospitalet \\ National University Hospital \\ Dept of Pediatrics \\ DK-2100 Copenhagen \\ Denmark
}

\author{
Keywords: interrupter \\ lung function \\ oscillometry \\ spirometry \\ transcutaneous measurements of oxygen \\ whole body plethysmography \\ young children
}

Received: December 141994

Accepted after revision August 281995

This study was supported by grants from the Danish Ministry of Health and from Astra-Draco, Lund, Sweden.
Morbidity from chronic lung disease in young children is relatively high and is probably on the increase. In principle, measurement of lung function is essential for the diagnosis and the monitoring of such diseases. However, only children aged at least 6-8 yrs can be expected to co-operate reliably to perform reproducible forced respiratory manoeuvres $[1,2]$ and to tolerate measurements within a whole body plethysmograph. For children under this age, lung function measurements are rarely performed, except for research purposes in infants, who may be studied during sedation. In young children, lung function measurements are seldom documented in clinical practice and intervention studies. The clinical evaluation of lung function by auscultation appears to be an extremely insensitive indicator of bronchoconstriction [3-5]. In a recent study of young children, a fall in oxygen tension of up to $33 \%$ occurred in some subjects without audiblc wheeze [3]. Other investigators have found that at least a $30 \%$ fall in forced expiratory volume in one second (FEV1) is necessary before wheezing is heard [4]. Consequently, knowledge of the natural history, the prevalence andthe optimal treatment of chronic lung diseases in this age group is limited. The demand for an index applicable in a clinical setting for the evaluation of lung function in young children is accordingly compelling.

The aim of this study was to evaluate three techniques to measure lung function in awake young children. Techniques which required sedation of the child were not considered. The techniques also had to be noninvasive, to be acceptable for most young children, and to require only passive co-operation. Impedance measurements by the oscillation technique (ZIOS), resistance measurements by the interrupter technique (Rint), and transcutaneous measurements of oxygen tension $\left(P \mathrm{tc}, \mathrm{O}_{2}\right)$ all appear to fulfil these requirements. The accuracy of these three methods, i.e. their relationship to true airway resistance is not known, nor is it within the scope of this study to address this issue. Rather, these measures may be considered as indices of lung function. To evaluate their use for such a purpose, changes in airway resistance during methacholine challenge in young children were measured by whole body plethysmography and spirometry, respectively, and these measurements were compared to simultaneous measurements of ZIOS, Rint and $P \mathrm{tc}, \mathrm{O}_{2}$. 


\section{Patients and materials}

\section{Patients}

Children aged 4-6 yrs with suspected asthma were eligible for the study. All subjects were considered to suffer from asthma as recurrent symptoms were typical of asthma and reversible after administration of a $\beta_{2}$-agonist.

Forty eight children were screened in order to select the children who were capable of performing technically satisfactory and reproducible measurements of FEV1 and specific airway resistance ( $\mathrm{s} R \mathrm{aw}$ ) within a whole body plethysmograph. Twenty-three children were unable to perform such measurements. The remaining 25 children all proved co-operative and were included in the comparative study. Of the children included in the study, those who did not respond to the highest dose of methacholine with an increase in sRaw of more than $100 \%$ during meth acholine challenge were excluded from the final data analysis.

The study was approved by the Local Ethics Committee (01-268/93) and written informed consent was obtained from the parents of the children.

\section{Equipment}

Lung function measurements, including spirometry and resistance measurements by whole body plethysmography, as well as the impulse oscillometry technique and the interrupter technique, were performed with a Master Screen unit (E. Jäeger gmbH, Würzburg, Germany) and processed on a Compaq 486/66 MHz computer. The pneumotachograph and whole body plethysmograph fulfilled the specifications recommended by the European Commission [6]. Corrections were made for resistance and dead space of the system. The oscillometry equipment fulfilled the standard recommendations [7]. All flow and volume measurements were corrected to body temperature and pressure, saturated with water vapour (BTPS) conditions and the equipment was calibrated once daily.

Measurements of $P \mathrm{tc}, \mathrm{O}_{2}$ and transcutaneous carbon dioxide tension $\left(P \mathrm{tc}, \mathrm{CO}_{2}\right)$ were made using the Radiometer TCM3 unit (Radiometer, Copenhagen). Dosimetry was performed with a Wright nebulizer adapted to the APS dosimeter (E. Jäeger gmbH, Würzburg, Germany).

\section{Methods}

\section{FEVI and forced vital capacity (FVC)}

Maximum expiratory flow volume curves were obtained by means of a heated pneumotachograph equipped with a differential pressure transducer. The flow signal was recorded by a computer which calculated both FEV1 and FVC. Three technically satisfactory forced expiratory manoeuvres were performed, and the manoeuvre with the highest sum of FVC and FEV1 was used as the final measurement.

\section{sRaw}

sRaw was measured in a constant volume whole body plethysmograph and was defined as the ratio between the change in inspiratory and expiratory pressures and associated respiratory flow rates. Measurements of these parameters were initiated when the subject had been seated inside the plethysmograph for at least $1 \mathrm{~min}$. The air inhaled by the subject was neither heated nor humidified. Drift in the box-pressure was compensated for by the "software", according to the principles described by SMIDT et al. [8]. Measurements were carried out during normal tidal breathing and no attempts were made to make the subjects pant. Five technically satisfactory measurements were sought. No measurement was disregarded, except when an artifact due to either a leak from the face mask, swallowing, coughing or vocalization was discovered on-screen. When this occurred the measurements were repeated until five undisturbed measurements were obtained. The median value from five such sequential cycles was used for the final result.

\section{ZIOS}

Impedance measurements were performed by impulse oscillometry (IOS) [9]. IOS is based on measurement of the relationship between an external pressure pulse applied to the respiratory system and the resulting respiratory airflow. The spectral ratio of the amplitude of the pressure wave signal to the resulting flow signal constitutes the impedance $(Z)$ of the respiratory system, from which the total resistance $(R \mathrm{rs})$ and the reactance $\left(X_{\mathrm{rs}}\right)$ of the respiratory system can be calculated [9-13].

With $0.2 \mathrm{~s}$ intervals brief pulses containing a continuous power spectrum ranging $0-100 \mathrm{~Hz}$ were generated by a loudspeaker. The pressure and flow fluctuations superimposed on the spontaneous breathing were measured at the mouth by means of two differential pressure transducers (Sensym SLP 004, Sensor Technics), which had a sensitivity of $\pm 10 \mathrm{mBar}$. The dynamic of the transducer is higher than $500 \mathrm{~Hz}$, and in connection with the pneumotachograph the $3 \mathrm{~dB}$ cut-off frequency is $50 \mathrm{~Hz}$. Without correction function the common mode rejection ratio is higher than $60 \mathrm{~dB}$ up to $50 \mathrm{~Hz}$. When varying the load from 0 to infinity, the system pressure varies from 0 to $0.32 \mathrm{kPa}$. When loaded with an impedance of $0.2 \mathrm{kPa} \cdot \mathrm{L}^{-1}$ the peak-to-peak pressure is above $0.2 \mathrm{kPa}$. At flow rates below $1 \mathrm{~L} \cdot \mathrm{s}^{-1}$ the pneumotachograph is linear within $3 \%$. The digitized pressure and flow signals were sampled at a rate of $200 \mathrm{~Hz}$ and fed into a fast Fourier transformation (FFT), which transforms the complex pulse signals into their elementary sinusoidal components [10]. The frequency resolution was defined by the FFT to $3.125 \mathrm{~Hz}$ in the range $0-50 \mathrm{~Hz}$. The FFTspecific fix points with $3.125 \mathrm{~Hz}$ distance were used in the averaging procedure in the application. After proper filtering, the values for $R \mathrm{rs}$ and $X_{\mathrm{rs}}$ obtained from each impulse were calculated in the frequency range $5-35 \mathrm{~Hz}$.

In the data-processing software, several features were applied in order to secure a linear model calculation and 
to improve the signal-to-noise ratio. A correction of baseline was applied in order to reduce the influence of the harmonics of the subjects breathing, accomplished by a correction derived from the difference between pressure and flow measurements at the start and at the end of each impulse, respectively. The content of harmonics of the breathing pattern was checked by defining 96 sampling points equal to zero to follow the 32 data points sampled at each impulse, as this enabled the FFT analysis down to $3 \mathrm{~Hz}$. Recordings containing a higher amount of harmonics were disregarded, which was also the case for measurements which showed a disproportion of the resolution of the pressure and flow signal.

The loud-speakcr was mounted on a Y-tubing, and the dead-space of Y-tubing and the combined pneumotachograph, pressure transducer and mouthpiece was $150 \mathrm{~mL}$. Fresh air was assured through the mesh of the terminating resistor mounted on the Y-tubing. The system was regularly calibrated against a reference impedance of $0.2 \mathrm{kPa} \cdot \mathrm{L}^{-1} \cdot \mathrm{s}$.

During data acquisition, pressure and flow fluctuations were displayed on-line together with the spirometry curve. Thirty seconds of continuous technically satisfactory measurements were sought. Whenever disturbance of the measurements was observed, the measurements were prolonged until $30 \mathrm{~s}$ of undisturbed measurements were obtained. Thereafter, no further sorting of the data was carried out and the calculated results were retained. The results presented are, thus, mean values of calculations from such $30 \mathrm{~s}$ measurements (approximately 150 pulses).

\section{Rint}

Respiratory resistance is, in principle, an estimate of the total resistance of the respiratory system as determined from the respiratory airflow and the driving airway pressure difference between the alveoli and the exterior as estimated from mouth pressure $(P$ mo $)$ during a brief interruption of airflow. Alveolar pressure is assumed to equilibrate with $P$ mo during this occlusion. During occlusion, $P$ mo is influenced by the resistance of the lung tissue and the chest wall in addition to the compliance of the upper airways, including the mouth $[14,15]$. The compliance of the latter may delay the equilibration between the alveoli and $P$ mo causing underestimation of the alveolar pressure. However, the estimate of $P$ mo is equally affected by a number of technical choices made during adaptation of the principle. Pmo may be measured during inspiration or expiration. In this study, $P$ mo was measured during inspiration, as differences in glottic opening are more likely to affect measurements during expiration [16]. Several principles have been suggested for estimating the alveolar pressure from the $P$ mo recording [17]. Our equipment applied the algorithm described by VAN DER PLAS and VoOREn [18] to estimate the $P$ mo from the time-pressure curve. According to this "opening interruption method", the $P$ mo is measured during the last part of the occlusion and measurement of airway flow is performed shortly after reopening of the shutter. During circumstances of increased airway resistance, the equilibration between the alveoli and $P$ mo is likely to be delayed and only airways contributing to airway flow are measured. Rint may, therefore, underestimate the airway disease, due to this mechanical nonhomogeneity of the lungs [19].

The interrupter technique was performed by interruption of the respiratory airflow by means of an interrupter mounted on the pneumotachograph. A pressure transducer placed between the interrupter and the subject was used for measuring Pmo during the interruption of airflow. The interrupter closed within $7 \mathrm{~ms}$ and was automatically activated in every second breath when a volume of $50 \mathrm{~mL}$ had been inspired. The interruption lasted for a total of $80 \mathrm{~ms}$ and Pmo was derived from the last $5 \mathrm{~ms}$. Airflow $\left(V^{\prime}\right)$ was measured over a period of $5 \mathrm{~ms}, 70 \mathrm{~ms}$ after the reopening of the interrupter. These settings were chosen based on pilot studies in children (Bisgaard, data on file).

Respiratory resistance (Rint) was calculated on-line from corresponding measurements of respiratory airflow and $P$ mo $\left(\right.$ Rint $\left.=P \mathrm{mo} / V^{\prime}\right)$. Five technically satisfactory measurements were sought. No measurement was disregarded, but when artifact was discovered on-screen, the measurements were continued to allow five undisturbed consecutive measurements to be made. The mean value of five measurements was used for the final analysis.

The combined resistance of the interrupter and pneumotachograph was $0.4 \mathrm{cmH}_{2} \mathrm{O} \cdot \mathrm{L}^{-1} \cdot \mathrm{s}$, and the dead space of the system was $160 \mathrm{~mL}$. The data sampling rate was $1,000 \mathrm{~Hz}$.

$$
P \text { tc }, \mathrm{O}_{2} \text { and } P \text { tc, } \mathrm{CO}_{2}
$$

$P$ tc, $\mathrm{O}_{2}$ and $P$ tc, $\mathrm{CO}_{2}$ were monitored transcutaneously by a heated electrode from which readings were continuously displayed and printed using a Radiometer TMC3. Calibration was performed with a calibrating gas containing $21.5 \% \mathrm{O}_{2}$ and $5 \% \mathrm{CO}_{2}$. The temperature of the electrode was $44^{\circ} \mathrm{C}$ during the measurement of blood gases. The electrode was placed on the upper part of the flexor side of the lower arm. The electrode was allowed to stabilize until readings had been stable for $5 \mathrm{~min}$. This usually occurred within $20 \mathrm{~min}$. After measurement of blood gases, the electrode was retested against the calibrating gas and if drift exceeded $0.3 \mathrm{kPa}$ during the period of measurement, a correction was made by linear interpolation, assuming that drift was constant over the whole period of measurement. The data used for calculating $P \mathrm{tc}, \mathrm{O}_{2}$ and $P \mathrm{tc}, \mathrm{CO}_{2}$ were obtained from reading the hard-copy curves printed during the measurement of blood gases. The results presented are median values of five readings at $1 \mathrm{~min}$ intervals beginning concurrently with the measurements of lung function.

\section{Lung function measurement procedure}

The child used a mouthpiece during spirometry. Spirometry was performed in a sitting position. $\mathrm{s} R$ aw, $R$ int and ZIOs measurements were performed with the child seated comfortably with the neck slightly extended. A facemask was used for these measurements. The face-mask was specially designed to provide stable access to the oropharynx 


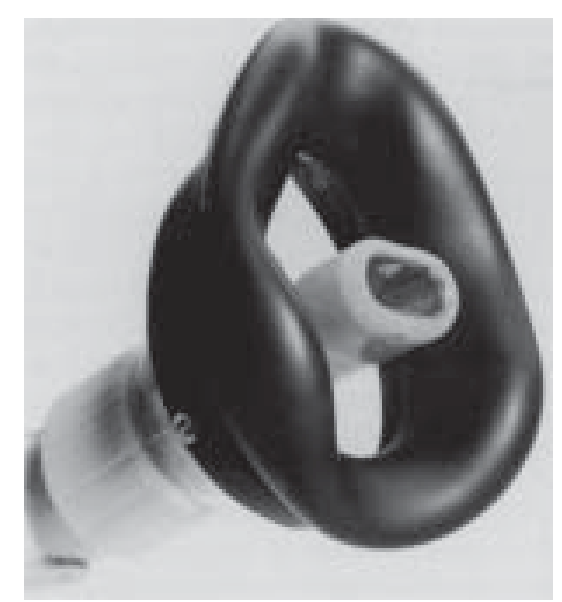

Fig. 1. - Face-mask with a built-in mouthpiece. This combination ensures that the young child breathes through the mouth.

andto prevent nose breathing. This was assured by a mouthpiece within a large mask. In addition, the large face-mask provided effective support to the cheeks (fig. 1).

Optimal passive co-operation by the children was enforced by showing video films during the procedure. Lung function measurements were performed in a fixed sequence (Rint, ZIOS, sRaw, FEV1), starting 3 min after the completion of each challenge step. $P \mathrm{tc}, \mathrm{O}_{2}$ and $P \mathrm{tc}, \mathrm{CO}_{2}$ were measured continuously.

Eight of the children from the study group were challenged on a separate day with the dose of methacholine producing an increase of $100 \%$ in $\mathrm{s} R \mathrm{aw}$. The airway resistance was subsequently traced for $15 \mathrm{~min}$ by measurements of Rint and sRaw every $5 \mathrm{~min}$.

\section{Methacholine challenge procedure}

Prior to methacholine challenge, all children were free of symptoms on the day of the study. The use of bronchodilators had also been omitted for at least $8 \mathrm{~h}$ prior to challenge. The methacholine solution $(4 \mathrm{~mL})$ was nebulized by using a Wright nebulizer driven by air at $21 \mathrm{psi}$ and a dynamic flow of $18 \mathrm{~L} \cdot \mathrm{min}^{-1}$. The nebulization was controlled by an APS dosimeter which initiated a brief nebulization of $0.6 \mathrm{~s}$ at the start of inspiration, delivering $2 \mathrm{mg}$ of solution per activation. The pressure was stable for more than $80 \%$ of the $0.6 \mathrm{~s}$ nebulization time. The inhalation of methacholine was performed during tidal breathing and the aerosol was inhaled through a mouthpiece while the children were wearing noseclips. The inhalation manoeuvre of the children was artificially prolonged by mounting a moderate resistance at the inlet valve of the system. The aerosol was delivered for eight respiratory cycles at each challenge step.

Saline was included as the first challenge step followed by methacholine bromide dissolved in unbuffered saline. The starting concentration of methacholine was $0.5 \mathrm{mg} \cdot \mathrm{mL}^{-1}$ followed by doubling concentrations to a maximum of $64 \mathrm{mg} \cdot \mathrm{mL}^{-1}$. Increasing doses of methacholine were inhaled until: 1) sRaw increased by at least $100 \%$; or 2) the highest dose of methacholine was reached; or 3) mild clinical signs of airway obstruction were apparent; or 4) the child complained of discomfort. Terbutaline sulphate $0.5 \mathrm{mg}$ was inhaled via a pressurized metered-dose inhaler plus large-volume spacer subsequent to the measurements after the last challenge. Lung function was measured before and after the initial saline inhalation, as well as after each methacholine inhalation and $15 \mathrm{~min}$ after the terbutaline inhalation.

\section{Statistical evaluation}

The baseline reproducibility for each technique was assessed by the within-subject standard deviation (SD) and the coefficient of variation (CV\%). The withinsubject SD was calculated from the difference between lung function measurements before and after inhalation of saline divided by $\sqrt{ } 2$. The individual mean baseline values showed no correlation with the absolute differences within baseline measurements as evaluated from graphic plots, i.e. the within-subject SD is independent of the mean level. The coefficient of variation (CV\%) was computed as the within-subject SD of the baseline in percentage of the mean In the case of reactance measurements the numeric values were used for the computation. In order to compare the performance of the techniques, the lung function measurements during challenge were transformed into an index taking into account the baseline reproducibility of each technique as described below:

$$
\text { SD-index }=\frac{\begin{array}{c}
\text { Change in lung function measurements from } \\
\text { postsaline measurement }
\end{array}}{\text { Within-subject SD }}
$$

The so-index transforms the absolute changes in lung function measurements during challenge into multiples of the baseline reproducibility of the individual technique. This transformation enables direct comparison of measurements, despite the differences between the baseline reproducibility of individual techniques.

The level of methacholine challenge achieved by each subject was indicated as the rank-order of challenge, i.e. the highest dose, the second highest dose etc., rather than by the actual dose of methacholine administered. This improved the possibility of comparing lung function measurements between the children despite their different sensitivity to methacholine challenge.

For all techniques, dose-response curves were constructed by plotting the changes in lung function, using the mean so-index value, against the corresponding rank of methacholine challenge. The sensitivity of the methods was evaluated from: 1) the threshold concentration (TC) causing a change in the lung function measurement of $3 \times \mathrm{SD}$ (TC3SD); and 2) the slope of the dose-response curve (A so-index/dose step), i.e. change in so-index relative to the change in dose level. To estimate TC3SD, linear interpolation was performed between the values surrounding the TC3SD value for each patient and method. To estimate the slope for each method. a linear regression model was fitted to the dose-response curve of each patient. For 
the comparisons between methods with regard to TC3SD values and slopes, an analysis of variance was performed based on the model patient and method.

Lung function before and after the administration of a $\beta_{2}$-agonist was compared by the Wilcoxon test for matched pairs. The central tendency was depicted by the mean value. Values of $\mathrm{p}$ less than 0.05 were considered significant.

\section{Results}

Twenty five children cntered the study and underwent methacholine challenge. Four children did not exhibit a $100 \%$ increase in sRaw following the maximal dose of methacholine and were accordingly excluded from the final data analysis. The 21 children fulfilling the inclusion criteria comprised 10 girls and 11 boys, mean age 5 yrs (range 4-6 yrs) and mean height $117 \mathrm{~cm}$ (range 110 $123 \mathrm{~cm})$. All children were treated with a $\beta_{2}$-agonist on an as-required basis. Sixteen children were treated with inhaled steroids; 14 with budesonide daily in doses ranging $100 \mu \mathrm{g}$ to $800 \mu \mathrm{g}$ and two with beclomethasone dipropionate daily in doses of $200 \mu \mathrm{g}$, all inhaled from pressurized metered-dose inhalers plus spacer device. Baseline lung function is presented in table 1. Due to technical reasons, ZIos and $P_{\mathrm{tc}}, \mathrm{O}_{2}$ measurements are absent for two children and three children, respectively.
The mean time from the beginning to the end of one set of measurements was $9.2 \mathrm{~min}$. In the time-effect study performed in a subgroup of children, the $R$ int as well as sRaw was reduced to $87 \%$ of its maximum 10 min after inhalation of methacholine.

The indices of Zıos, Rrs and $X$ rs were calculated at 5, 10,15 , and $35 \mathrm{~Hz}$ and compared at both baseline and at maximal response (table 2 and fig. 2). Rrs and $X$ rs both exhibited the strongest response at $5 \mathrm{~Hz}$. Reactance exhibited a stronger response than resistance at any frequency. ZIos data acquisition was extended to $30 \mathrm{~s}$ in this study, but recalculation of the results showed that this could be reduced to $5 \mathrm{~s}$ without significant effect on the outcome.

The baseline reproducibility is given as the withinsubject SD and the CV\% of the methods in table 1 . The order of CV\% for the methods was $P$ tc, $\mathrm{O}_{2}<\mathrm{FEV} 1<R \mathrm{rs}<$ $R$ int $<\mathrm{s} R$ aw $<X$ rs . The change in lung function at maximal dose is shown in table 1.

The mean dose-response relationship between the level of challenge and SD-index of sRaw, FEV1, Xrs, Rrs, Rint and $P$ tc, $\mathrm{O}_{2}$ is shown in figure 3 .

TC3SD and slope of the dose-response relationship is presented in table 1 . The order of sensitivity based on these characteristics of the methods was: $X \mathrm{rs}>\mathrm{s} R \mathrm{aw}>P \mathrm{tc}, \mathrm{O}_{2}$ $>\mathrm{FEV} 1>R \mathrm{rs}>\operatorname{Rint}$. Xrs showed a significantly steeper doseresponse curve in comparison with all subsequent meth

Table 1. - Comparison of the "gold standard" measurements FEV 1 and sRaw with concomitant measurements of indices of lung function as measured by the Zıos components resistance $(R \mathrm{rs} 5)$ and reactance $\left(X_{\mathrm{rs} 5}\right)$, and $R \mathrm{int}$ and $P_{\mathrm{tc}}, \mathrm{O}_{2}$

\begin{tabular}{|c|c|c|c|c|c|c|}
\hline & $\begin{array}{l}\mathrm{FEV}_{1} \\
\mathrm{~L}\end{array}$ & $\begin{array}{c}\mathrm{s} R \mathrm{aw} \\
\mathrm{kPa} \cdot \mathrm{s}^{-1}\end{array}$ & $\begin{array}{c}R \mathrm{rs} 5 \\
\mathrm{kPa} \cdot \mathrm{s} \cdot \mathrm{L}^{-1}\end{array}$ & $\begin{array}{c}X_{\mathrm{rs} 5} \\
\mathrm{kPa} \cdot \mathrm{s} \cdot \mathrm{L}^{-1}\end{array}$ & $\begin{array}{c}R_{\text {int }} \\
\mathrm{kPa} \cdot \mathrm{s} \cdot \mathrm{L} \cdot 1\end{array}$ & $\begin{array}{l}P \mathrm{tc}, \mathrm{O}_{2} \\
\mathrm{kPa}\end{array}$ \\
\hline Baseline & $\begin{array}{c}1.08 \\
\pm 0.22\end{array}$ & $\begin{array}{c}1.09 \\
\pm 0.20\end{array}$ & $\begin{array}{c}0.93 \\
\pm 0.26\end{array}$ & $\begin{array}{l}-0.24 \\
\pm 0.1\end{array}$ & $\begin{array}{c}1.18 \\
\pm 0.21\end{array}$ & $\begin{array}{c}11.8 \\
\pm 0.84\end{array}$ \\
\hline $\begin{array}{l}\text { Maximal bronchial } \\
\text { obstruction }\end{array}$ & $\begin{array}{c}0.79 \\
\pm 0.16\end{array}$ & $\begin{array}{l}2.44 \\
\pm 0.46\end{array}$ & $\begin{array}{c}1.35 \\
\pm 0.39\end{array}$ & $\begin{array}{l}-0.80 \\
\pm 0.26\end{array}$ & $\begin{array}{c}1.87 \\
\pm 0.40\end{array}$ & $\begin{aligned} & 9.3 \\
\pm & 1.03\end{aligned}$ \\
\hline Post $\beta_{2}$-agonist & $\begin{array}{c}1.09 \\
\pm 0.22\end{array}$ & $\begin{array}{c}0.94 \\
\pm 0.14\end{array}$ & $\begin{array}{c}0.77 \\
\pm 0.18\end{array}$ & $\begin{array}{l}-0.136 \\
\pm 0.08\end{array}$ & $\begin{array}{c}0.9 \\
\pm 0.03\end{array}$ & $\begin{array}{l}11.71 \\
\pm 0.10\end{array}$ \\
\hline $\mathrm{p}=$ value $^{*}$ & $>0.1$ & $<0.01$ & $<0.01$ & $<0.001$ & $<0.001$ & $>0.1$ \\
\hline $\begin{array}{l}\text { Maximal change } \\
\text { in } \% \text { of baseline }\end{array}$ & $\begin{array}{l}-25 \\
\pm 11\end{array}$ & $\begin{array}{l}+150 \\
\pm 36\end{array}$ & $\begin{array}{l}+148 \\
\pm 39\end{array}$ & $\begin{array}{l}-300 \\
\pm 216\end{array}$ & $\begin{array}{l}+66 \\
\pm 34\end{array}$ & $\begin{array}{l}-22 \\
\pm 7\end{array}$ \\
\hline $\begin{array}{l}\text { Within-subject SD } \\
\text { of baseline } \\
\text { measurements }\end{array}$ & 0.05 & 0.14 & 0.10 & 0.04 & 0.14 & 0.34 \\
\hline CV $\%$ & 5 & 13 & 10 & 17 & 12 & 3 \\
\hline TC3SD conc. steps ${ }^{\#}$ & $\begin{array}{c}3.1 \\
(2.8-3.5)\end{array}$ & $\begin{array}{c}2.2 \\
(1.9-2.5)\end{array}$ & $\begin{array}{c}2.9 \\
(2.5-3.3)\end{array}$ & $\begin{array}{c}2.1 \\
(1.7-2.4)\end{array}$ & $\begin{array}{c}3.2 \\
(2.8-3.6)\end{array}$ & $\begin{array}{c}2.5 \\
(2.1-2.9)\end{array}$ \\
\hline $\begin{array}{l}\text { Slope of dose- } \\
\text { response curve } \\
\text { SD-index/conc. step }\end{array}$ & $\begin{array}{c}1.5 \\
(1.1-1.8)\end{array}$ & $\begin{array}{c}2.3 \\
(1.9-2.7)\end{array}$ & $\begin{array}{c}1.3 \\
(0.9-1.7)\end{array}$ & $\begin{array}{c}3.5 \\
(3.1-3.9)\end{array}$ & $\begin{array}{c}1.2 \\
(0.8-1.6)\end{array}$ & $\begin{array}{c}1.8 \\
(1.4-2.2)\end{array}$ \\
\hline
\end{tabular}

Values are presented as mean \pm SD. \#: 95\% confidence limit in parenthesis. *: baseline versus post $\beta 2$-agonist. FEV1: forced expiratory volume in one second; $s R$ aw: specific airways resistance; ZIOS: impedance measured by the impulse oscillation technique; $R$ rs5: resistance of the respiratory system at $5 \mathrm{~Hz} ; X \mathrm{rs} 5$ : reactance of the respiratory system at $5 \mathrm{~Hz}$; Rint: repiratory resistance measured by the interrupter technique; $\mathrm{Ptc}_{\mathrm{tc}} \mathrm{O}_{2}$ : transcutaneous oxygen tension; $\mathrm{CV}$ : coefficient of variation; TC3SD: threshold concentration causing a change in the lung function measurement of $3 \mathrm{XSD}$. 
Table 2. - Frequency dependence of the impedence(Zıos) indices, reactance (Xrs) and resistance (Rrs) at baseline and during bronchial obstruction (bronch. obs.)

\begin{tabular}{lcccc}
\hline & $5 \mathrm{~Hz}$ & $10 \mathrm{~Hz}$ & $15 \mathrm{~Hz}$ & $35 \mathrm{~Hz}$ \\
\hline $\begin{array}{l}\mathrm{Xrs} \text { baseline } \\
\mathrm{kPa} \cdot \mathrm{s} \cdot \mathrm{L}^{-1}\end{array}$ & $-0.24( \pm 0.10)$ & $-0.23( \pm 0.10)$ & $-0.14( \pm 0.08)$ & $0.18( \pm 0.06)$ \\
$\begin{array}{l}\mathrm{Xrs} \text { bronch. obs. } \\
\mathrm{kPa} \cdot \mathrm{s} \cdot \mathrm{L} \cdot \mathrm{L}^{-1}\end{array}$ & $-0.80( \pm 0.26)$ & $-0.62( \pm 0.19)$ & $-0.38( \pm 0.16)$ & $0.04( \pm 0.09)$ \\
$\begin{array}{l}\mathrm{Rrs} \text { baseline } \\
\mathrm{kPa} \cdot \mathrm{s} \cdot \mathrm{L}^{-1}\end{array}$ & $0.93( \pm 0.26)$ & $0.70( \pm 0.17)$ & $0.59( \pm 0.14)$ & $0.66( \pm 0.10)$ \\
$\begin{array}{l}\mathrm{Rrs} \text { bronch. obs. } \\
\mathrm{kPa} \cdot \mathrm{s} \cdot \mathrm{L}^{-1}\end{array}$ & $1.35( \pm 0.39)$ & $0.82( \pm 0.23)$ & $0.65( \pm 0.17)$ & $0.71( \pm 0.13)$ \\
\hline
\end{tabular}

Values are mean, \pm SD in parenthesis. For abbreviations see legend to table 1.

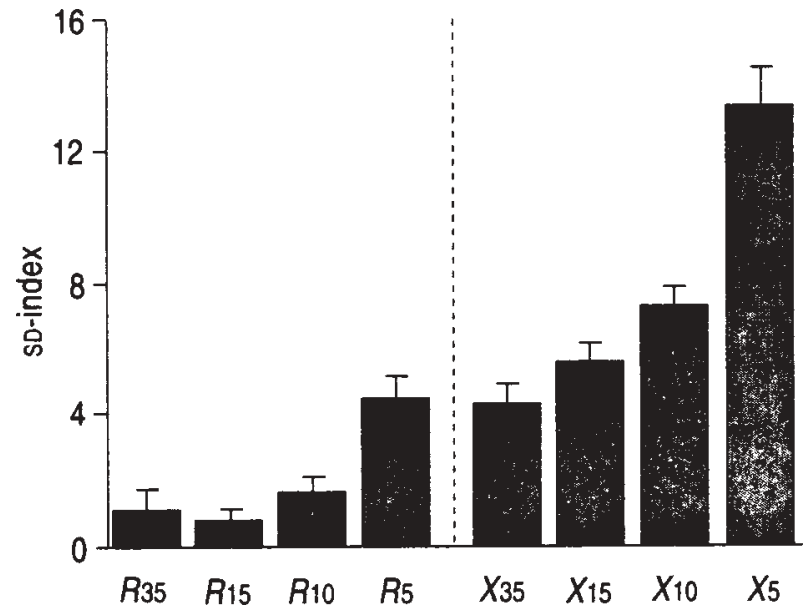

Fig. 2. - Impedence measured by the impulse oscillation technique (ZIos) at maximal bronchial obstruction computed as its resistance $\left(R_{\mathrm{rs}}\right)$ as well as its reactance $\left(X_{\mathrm{rs}}\right)$ components at discrete frequencie s from $5-35 \mathrm{~Hz}$. $X_{\mathrm{rs}}$ at $5 \mathrm{~Hz}$ is more sensitive to bronchial challenge than the other estimates of ZIos. Measurements were performed in 21 young asthmatic children. Bars indicate mean+SEM.

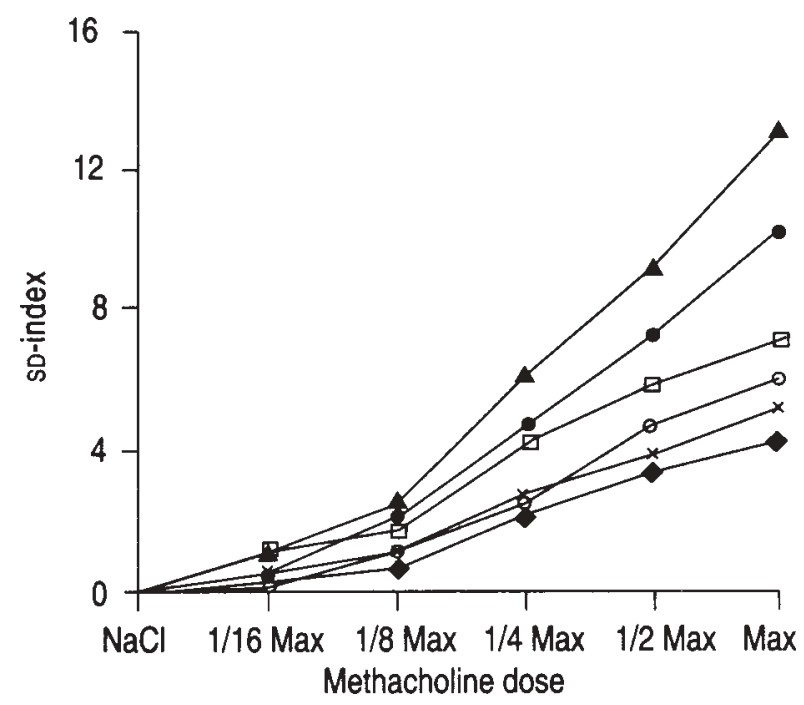

Fig. 3. - Dose-response curve of the change in lung function variables expressed as SD-index against increased doses of inhaled methacholine expressed as a fraction of maximal dose, in 21 young asthmatic children. Between each dose-step, lung function was measured by $R_{\text {int }}(-\times-), X_{\mathrm{rs} 5}(-\mathbf{-}-), R_{\mathrm{rs} 5}(-\bullet)$ and $\mathrm{s} R$ aw $(-\bullet-)$ and FEV1 (- - ) in consecutive order, whilst $P_{\mathrm{tc}}, \mathrm{O}_{2}(-\square-)$ was measured continuously. Rint: respiratory resistance measured by the interrupter technique; Xrs5: reactance of the respiratory system at $5 \mathrm{~Hz}$; Rrs5: resistance of the respiratory system at $5 \mathrm{~Hz}$; sRaw: specific airways resistance; FEV1: forced expiratory volume in one second; $P \mathrm{tc}_{\mathrm{O}} \mathrm{O}_{2}$ : transcutaneous oxygen tension. ods and provided a significantly lower TC3sD than FEV1. $P$ tc, $\mathrm{O}_{2}$ also provided a significantly lower TC3sD than FEV1. $P$ tc, $\mathrm{CO}_{2}$ did not exhibit detectable changes during the challenge procedure.

All methods reflected the reversal of lung function measurements to baseline levels after inhalation of a $\beta_{2}$-agonist (table 1). Furthermore, subclinical airway obstruction was revealed at baseline as a significantly reduced airway resistance after inhalation of a $\beta_{2}$-agonist in comparison to baseline measurements. This was reflected by sRaw, $X \mathrm{rs}, R \mathrm{rs}$ and $R$ int $(\mathrm{p}<0.01)$, although not by FEV 1 and $P$ tc, $\mathrm{O}_{2}$ measurements (table 1 ).

\section{Discussion}

Zios, Rint and $P$ tc, $\mathrm{O}_{2}$ measurements exhibited convincing covariation with the "gold standard" measurements of sRaw and FEV1 during methacholine-induced bronchial obstruction. The methods are likely to reflect different aspects of lung function. Whole body plethysmography is a measurement of airway resistance alone; ZIOS reflects the impedance of the whole respiratory system; Rint reflects total pulmonary airflow resistance plus some fraction of chest wall resistance; whereas, spirometry is a flowvolume measurement and only indirectly reflects airway resistance; and $P \mathrm{tc}, \mathrm{O}_{2}$ is an indirect measurement of ventilatory and vascular function. Direct correlation can, therefore, not be expected, but the observed covariation attests to their usefulness as semi-quantitative measurements related to lung function in young children.

The magnitude of the response varied considerably between the methods applied. However, the baseline reproducibility also varied, as reflected in the withinsubject SD and the CV\% (table 1). FEV1 and $P$ tc, $\mathrm{O}_{2}$ exhibited good reproducibility as opposed to $\mathrm{s} R \mathrm{aw}, X \mathrm{rs}, R \mathrm{rs}$ and $R$ int. To facilitate the comparison of the response of the different methods, we estimated the SD-index, which indicates the absolute increase in multiples of the baseline reproducibility (fig. 3). The order of sensitivity was $X$ rs $>$ sRaw $>P_{\mathrm{tc}}, \mathrm{O}_{2}>\mathrm{FEV} 1>R \mathrm{rs}>R$ int. $X$ rs was significantly more sensitive than FEV1. The sensitivity of $P \mathrm{tc}, \mathrm{O}_{2}$ did not differ significantly from that of SRaw, but it was significantly better than FEV1. All of the methods applied reflected the reversal of the obstruction subsequent to inhalation of a $\beta_{2}$-agonist. $X \mathrm{rs}, R \mathrm{rs}, \mathrm{s} R$ aw and $R$ int but not $P \mathrm{tc}, \mathrm{O}_{2}$ and $\mathrm{FEV} 1$ revealed the subclinical bronchial obstructionof the children prior to methacholine challenge, 
as reflected in the significantly reduced airway resistance after inhalationof a $\beta_{2}$-agonist as compared to baseline measurements.

Whole body plethysmography and spirometry are considered "gold standard" measurements of airway resistance and flow. However, children under 6-8 yrs are seldom able to reliably and reproducibly perform the manoeuvres required for these techniques [1,2]. The ZIOS and Rint measurements are performed during normal tidal breathing, they require only passive co-operation, and each measurement may be accomplished within less than $15 \mathrm{~s}$. The methods are also noninvasive, apart from the closely fitted face-mask equipped with a mouthpiece. The general acceptance of these methods is, therefore, good among young children and the methods can probably be performed in most awake young children.

The accuracy of $\mathrm{sRaw}$ and FEV1, i.e. their relationship to true airway resistance, is generally accepted as good. The accuracy of ZIOS and Rint is, however, less clear. The accuracy of $P \mathrm{tc}, \mathrm{O}_{2}$ is well-known with respect to arterial oxygen tension $\left(P \mathrm{tc}, \mathrm{O}_{2}\right)$, and they seem to correlate well in infants and young children [20] and even in adults [21]. However, the accuracy of $P \mathrm{tc}, \mathrm{O}_{2}$ as a reflection of lung function is obscure and may be confounded by vascular flow changes.

sRaw was calculated from the relationship of respiratory flow and the corresponding box-pressure precluding separate measurements of total gas volume (TGV) from breathing manoeuvres against a shutter [22]. Measurements of sRaw are discriminative to airway pathology as documented previously in studies of histamine [23] and methacholine-induced bronchial obstruction [24].

The impedance of the respiratory system, ZIos, was studied using impulse oscillometry, a special form of forced oscillation technique. In this case, the respiratory flow of the subject is overlaid by short time pressure pulses emitted from a loudspeaker. Based on the airflow response, the pulmothoracic impedance can be calculated. The impedance is estimated as the spectral ratio between pressure and flow in the frequency range 5$35 \mathrm{~Hz}$, and is resolved into its two components, the $R \mathrm{rs}$ (resistance of the respiratory system) and the $X$ rs (reactance of the respiratory system) [9-13]. The indices derived from the IOS are, in principle, comparable to those obtained by the pseudorandom noise method of LANDSER et al. [25]. The latter method applies a statistical coherence function for evaluation of the signal-to-noise ratio of the measurements. The IOS application improves on the signal-to-noise ratio by compensating the influence of the harmonics of breathing and rejecting extreme measurements. Furthermore, the IOS provides on-line display of the volume, flow, and pressure changes, allowing evaluation of the quality of measurements.

The indices of IOS and other oscillometrics exhibit frequency dependency in young children, probably reflecting the heterogeneity of the lung and a frequencydependent redistribution of the oscillatory flow between different compartments $[11,26]$. $X$ rs is more discriminative than $R$ rs for detecting impaired lung function, and lower frequencies are more discriminative than higher frequencies [24, 27]. Accordingly, our measurements of Rrs as well as $X$ rs exhibited a frequency dependency, with more profound changes in the lower frequency domain and more profound changes in $X_{\mathrm{rs}}$ as compared to $R$ rs (fig. 2 and table 2).

The pressure wave is dampened by compliant upper airways. Thus, it has been suggested that the cheeks of the child should be stabilized to reduce this problem [28], or that the pressure input should be applied around the head, which minimizes transmural pressure variations across upper airway walls [29]. In the latter, the child's head is enclosed in a box and the opening at the level of the neck is sealed off by means of a rubber collar. However, young children may not tolerate the box. Furthermore, the head-box does not seem to improve the accuracy [30] or the sensitivity [31] of the respiratory impedance measurements.

Young children are unlikely to comply with the requirement for a closely-fitted mouthpiece and noseclips, and within an ordinary face-mask they may choose to breathe through the nose. Any such leak through the nose or around the mouthpiece will adversely influence the measurements. Thus, we suggest the use of a face-mask large enough to stabilize the cheeks and equipped with a mouthpiece which ensures mouth breathing rather than nasal breathing. The acceptance of this combined face-mask mouthpiece was good in the present study. However, the face-mask with mouthpiece will not completely obliterate the artifact caused by the compliance of the upper airways. Bias from the upper airways will, however, tend towards underestimating the lower airway impedance. The sensitive response of the ZIOS in the present study is accordingly not due to artifact caused by interference from the upper airways.

Previous studies in young children have shown good correlations of the impedance measured by oscillometry to peak expiratory flow (PEF) during exercise-induced asthma in young children [32], to plethysmography during carbachol challenge $[24,33]$ and $\beta_{2}$-agonist inhalation [34], and to forced spirometry during allergen challenge [10], methacholine challenge [27] and histamine challenge [35]; as well as during baseline conditions [36, 37]. The impedance measured by oscillometry has, therefore, been suggested as a convenient alternative to forced spirometry measurements for the study of lung function and bronchial reactivity in children [24, 27, 38], although, in a recent study in 5 year old children measurements by the forced oscillation technique were found to be unreliable [3].

Rint is, in principle, an estimate of the total resistance of the respiratory system as determined from the airflow and the driving airway pressure difference between alveoli and the exterior as estimated from the mouth pressure $(P \mathrm{mo})$ during a brief interruption of airflow. Due to confounding variables and arbitrary choices that have be made prior to the calculation of $R$ int, absolute $R$ int measurements have no general acceptance. However, as an index of intraindividual short-term changes of lung function, it is apparently convenient and exhibits a high degree of covariation with FEV1 and sRaw measurements. Previous observations in children [39] and adults [40] have found a correlation between $R$ int and FEV1 and sRaw measurements, although a different algorithm for the $R$ int calculation was applied. The data from this study in young children 
confirm the covariation between $R$ int and sRaw as well as FEV1. Furthermore, the sensitivity of the Rint method appears comparable to that of FEV1 but less than that of sRaw.

Measurement of blood gases reflects the total outcome of respiratory and vascular conditions. It is appealing for its obvious relevance to the clinical state of the patient. Changes in $P$ tc, $\mathrm{O}_{2}$ during bronchial obstruction probably reflect ventilation-perfusion mismatch [41, 42]. These are generally assumed to reflect changes in the peripheral parts of the airways [43]. Although $P \mathrm{tc}, \mathrm{O}_{2}$ may not be an accurate measure of arterial oxygen tension $\left(P a, \mathrm{O}_{2}\right)$, $P$ tc, $\mathrm{O}_{2}$ and $P \mathrm{a}, \mathrm{O}_{2}$ covariate during acute asthma in young and in older children and even after inhalation of the potent vasodilator, the $\beta_{2}$-agonist $[20,21,43] . P_{\mathrm{tc}, \mathrm{O}_{2}}$ has previously been found to correlate to the clinical state [44], to respiratory impedance measurements [41, 45], and to spirometry [46], with a precision that compared favourably with the latter [47]. In this study, $P t_{c}, \mathrm{O}_{2}$ exhibited a covariation with the "gold standard" measurements of sRaw and FEV1. The sensitivity of the method was at least as good as that of FEV1, though apparently less so than plethysmography.

Changes in lung function were induced by methacholine inhalations. The different tests were applied after inhalation of methacholine in a fixed sequence of Rint, ZIos, sRaw and spirometry. $P \mathrm{tc}, \mathrm{O}_{2}$ was measured continuously. Any reduction in bronchial obstruction during this time would favour the sensitivity of the tests applied first. However, it was not feasible to randomize the sequence of lung function tests, as the maximal inspiratory effort during spirometry would cause a confounding bronchodilatation [48] and increase $P \mathrm{tc}, \mathrm{O}_{2}$ values. Furthermore, a randomized sequence would complicate the intricate procedure the young children had to perform during the repeated challenges. In a subgroup of children, the time-dependent weaning of bronchial obstruction revealed that airway obstruction stabilized within $87 \%$ of the initial degree of obstruction for at least $10 \mathrm{~min}$ after inhalation of methacholine, which is in accordance with previous reports [17, 49]. Our measurements were performed within this time period and are, accordingly, unlikely to be severely affected by time-dependent changes. The confounding time-effect relationship will most severely affect the spirometry measurements performed as the last measurement, yet not affect the comparison of ZIOS with sRaw, and Rint with sRaw, which were performed in close proximity.

The main conclusion of this study is that ZIOS, Rint and $P$ tc, $\mathrm{O}_{2}$ reflect changes in lung function upon methacholine bronchial challenge and $\beta_{2}$-agonist-induced bronchodilatation in young children of $4-6$ yrs with sensitivity comparable to that of sRaw and FEV1 measurements. Although the results may point in favour of ZIOS as the method of choice for estimates of lung function in young awake children during tidal breathing, Rint as well as $P \mathrm{tc}, \mathrm{O}_{2}$ are likely to provide additional aspects of lung function. It may, therefore, seem advisable to include all three methods for such purposes in future studies. The methods will allow future studies of the natural history as well as interventions in lung diseases of young children.

\begin{abstract}
Acknowledgements: The authors thank O.F. Pedersen (University of Aarhus, Denmark) and J. Reinstäedtler and H.J. Smith (Jäeger Würzburg) for fruitful criticism of the manuscript. T. Bengtsson is thanked for the statistical evaluation.
\end{abstract}

\section{References}

1. Sly PD, Robertson CF. A review of pulmonary function testing in children. J Asthma 1990; 27: 137-147.

2. Kanengiser S, Dozor AJ. Forced expiratory maneuvers in children aged 3 to 5 years. Pediatr Pulmonol 1994; 18: 144-149.

3. Wilson NM, Bridge P, Phagoo SB, Silverman M. The measurement of methacholine responsiveness in 5 year old children: three methods compared. Eur Respir J 1995; 8: 364-370.

4. Spence DPS, Bentley S, Evans DH, Morgan MDL. Effect of methacholine-induced bronchoconstriction on the spectral characteristics of breath sounds in asthma. Thorax 1992; 47 : 680-683.

5. Shim CS, Williams MH. Evaluation of the severity of asthma: patients versus physicians. Am J Med 1980; 68: 11-13.

6. Quanjer PH. Standardized lung function testing. Working Party Report "Standardization of Lung Function Tests", European Coal and Steel Community, Luxemburg. Bull Eur Physiopathol Respir 1983; 19 (Suppl. 5): 1-95.

7. Van de Woestijne KP, Desager KN, Duiverman EJ, Marchal F. Recommendations for measurement of respiratory input impedance by means of forced oscillation method. Eur Respir Rev 1994; 4: 19: 235-237.

8. Smidt U, Muysers K, Buchhaim W. Electronic compensation of differences in temperature and vapour between inspired and expired air and other signal handling in body plethysmography. Prog Respir Res 1969; 4: 39-49.

9. Vogel J, Smidt U. Impulse oscillometry. Frankfurt am Main, Pmi Verlagsgruppe GmbH, 1994.

10. Michaelson ED, Grassman ED, Peters WR. Pulmonary mechanics by spectral analysis of forced random noise. J Clin Invest 1975; 56: 1210-1230.

11. Solymar L, Aronsson P-H, Engström I, Bake B, Bjure J. Forced oscillation technique and maximal expiratory flows in bronchial provocation tests in children. Eur J Respir Dis 1984; 65: 486-495.

12. Solymar L, Aronsson PH, Bake B, Bjure J. Respiratory resistance and impedance magnitude in healthy children aged 2-18 years. Pediatr Pulmonol 1985; 1: 134-140.

13. Van Noord JA. Oscillation mechanics of the respiratory system: clinical applications and modelling. Thesis, Katholieke Universiteit, Leuven, 1990.

14. Bates JHT, Baconnier P, Milic-Emili J. A theoretical analysis of interrupter technique for measuring respiratory mechanics. J Appl Physiol 1988; 64: 2204-2214.

15. Bates JHT, Sly P, Kochi T, Martin JG. The effect of a proximal compliance on interrupter measurements of resistance. Respir Physiol 1987; 70; 310-312.

16. Stanescu DC, Pattijn J, Clément J, van de Woestijne KP. Glottis opening and airway resistance. J Appl Physiol 1972; 32: 460-466.

17. Phargoo SB, Watson RA, Pride NB, Silverman M. Accuracy and sensitivity of the interrupter technique for measuring the response to bronchial challenge in normal subjects. Eur Respir J 1993; 6: 996-1003.

18. van der Plas K, Vooren P. The "opening" interrupter. Eur J Respir Dis 1982; 63: 449-458. 
19. Eiser NM, Kerrebejn KF, Quanjer PH, (Eds) Guidelines for standardisation of bronchial challenges with (nonspecific) bronchoconstricting agents. Clin Respir Phys 1993; 19: 495-514.

20. Wennergren G, Engström I, Bjure J. Transcutaneous oxygen and carbon dioxide levels and a clinical scale for monitoring the acute asthmatic state in infants and young children. Acta Paediatr Scand 1986; 75: 465-469.

21. McDowell JW, Thiede WH. Usefulness of the transcutaneous $\mathrm{PO}_{2}$ monitor during exercise testing in adults. Chest 1980; 78: 853-855.

22. Dab I, Alexander F. A simplified approach to the measurement of specific airway resistance. Pediatr Res 1976; 10 996-999.

23. Dab I, Alexander F. On the advantages of specific airway resistance. Pediatr Res 1978; 12: 878-881.

24. Buhr W, Jörres R, Berdel D, Landsér FJ. Correspondence between forced oscillation and body plethysmography during bronchoprovocation with carbachol in children. Pediatr Pulmonol 1990; 8: 280-288.

25. Landser FJ, Nagels J, Demedts M, Billiet L, van de Woestijne KP. A new method to determine frequency characteristics of the respiratory system. J Appl Physiol 1976; 1: 101-106.

26. Solymar L, Aronsson PH, Sixt R. The forced oscillation technique in children with respiratory disease. Pediatr Pulmonol 1985; 1: 256-261.

27. Duiverman EJ. Neijens HJ, van der Snee-van Smaalen M, Kerrebejn KF. Comparison of forced oscillometry and forced expiration for measuring dose-related responses to inhaled methacholine in asthmatic children. Clin Respir Phys 1986; 22: 433-436.

28. Peslin R, Duivier C, Gallina C, Cervantes P. Upper airway artefact in respiratory impedance measurements. Am Rev Respir Dis 1985; 132: 712-714.

29. Peslin R, Duvivier C, Didelon J, Gallina C. Respiratory impedance measured with head generator to minimize upper airway shunt. J Appl Physiol 1985; 59: 17901795 .

30. Marchal F, Mazurek H, Habib M, Duvivier C, Derelle J, Peslin R. Input respiratory impedance to estimate airway hyperreactivity in children: standard method versus head generator. Eur Respir J 1994; 7: 601-607.

31. Govaerts E, Cauberghs M, Demedts M, Van de Woestijne KP. Head generator versus concentional technique in respiratory input impedance measurements. Eur Respir Rev 1994; 4: 143-149.

32. Lenney W, Milner AD. Recurrent wheezing in the preschool child. Arch Dis Child 1978; 53: 468-473.

33. Chinet T, Pelle G, Macquin-Mavier I, Lorino H, Harf A. Comparison of the dose-response curves obtained by forced oscillation and plethysmography during carbachol inhalation. Eur Respir J 1988; 1: 600-605.

34. Nussbaum E, Galant SP. Measurement of total respiratory resistance in children by a modified forced oscillation method. Pediatr Res 1984; 18: 139-145.

35 Lebecque P, Spier S, Lapierre JG, Lamarre A, Zinman R, Coates AL. Histamine challenge test in children using forced oscillation to measure total respiratory resistance. Chest 1987 ; 92: 313-318.

36. König P, Hordvik NL, Pimmel RL. Forced random noise resistance determination in childhood asthma. Chest 1984 86: 884-890.

37. Lebecque P, Desmond K, Swartebroeckx Y, Dubois P, Lulling J, Coates A. Measurement of respiratory system resistance by forced oscillation in normal children: a comparison with spirometric values. Pediatr Pulmonol 1991; 10: 117-122.

38. Holmgren D, Engström I, Bjure J, Sixt R, Åberg N. Respiratory resistance and transcutaneous $\mathrm{PO}_{2}$ during histamine provocation in children with bronchial asthma. Pediatr Pulmonol 1993; 15: 168-174.

39. Carter ER, Stecenko AA, Pollock BH, Jaeger MJ. Evaluation of the interrupter technique for the use of assessing airway obstruction in children. Pediatr Pulmonol 1994; 17: 211-217.

40. Chowienczyk PJ, Lawson CP, Lane S, et al. A flow interruption device for measurement of airway resistance. Eur Respir J 1991; 4: 623-628.

41. Hedlin G, Freyschuss U, Hedenstierna G. Histamineinduced asthma in children: effects on the ventilationperfusion relationship. Clin Physiol 1985; 5: 19-34.

42. Burke TV, Küng M, Burki NK. Pulmonary gas exchange during histamine-induced bronchoconstr iction in asthmatic subjects. Chest 1989; 96: 752-756.

43. Holmgren D, Sixt R. Transcutaneous and arterial blood gas monitoring during acute asthmatic symptoms in children. Pediatr Pulmonol 1992; 14: 80-84.

44. Wennergren G, Engström I, Bjure J. Transcutaneous oxygen and carbon dioxide levels and a clinical symptom scale for monitoring the acute asthmatic state in infants and young children. Acta Paediatr Scand 1986; 75: 465469.

45. Wilson NM, Phagoo SB, Silverman M. Use of transcutaneous oxygen tension, arterial oxygen saturation, and respiratory resistance to assess the response to inhaled methacholine in asthmatic children and normal adults. Thorax 1991; 46 : 433-437.

46. Eber E, Varga E-M, Zach MS. Cold air challenge of airway reactivity in children: a correlation of transcutaneously measured oxygen tension and conventional lung functions. Pediatr Pulmonol 1991; 10: 273-277.

47. Phagoo SB, Wilson NM, Silverman M. Repeatability of methacholine challenge in asthmatic children measured by change in transcutaneous oxygen tension. Thorax 1992; 47: 804-808.

48. Orehek J, Delpierre NS, Beaupre A. Influence of the previous deep inspiration on the spirometric measurement of provoked bronchoconstriction in asthma. Am Rev Respir Dis 1981; 123: 269-272.

49. Cartier A, Malo J-L, Bégin P, Sestier M, Martin RR. Time course of the bronchoconstriction induced by inhaled histamine and methacholine. J Appl Physiol: Respirat Environ Exercise Physiol 1983; 54: 821-826. 